\title{
Batalha Naval Matemática: um relato da aplicação de jogos matemáticos no ensino fundamental
}

\section{Naval Battle Mathematics: an account of the application of mathematical games in elementary school}

\author{
André Tavares Gonçalves ${ }^{1}$ \\ Wálmisson Régis de Almeida ${ }^{2}$ \\ José Fernandes da Silva ${ }^{3}$
}

\begin{abstract}
Resumo: O artigo apresenta o relato da aplicação do jogo Batalha Naval Matemática como elemento lúdico para o ensino de Matemática. A atividade foi aplicada em uma turma do $7^{\circ}$ ano do Ensino Fundamental II visando discutir o tema "equações de $1^{\circ}$ grau". O jogo segue a mesma lógica do tradicional "Batalha Naval" em termos de objetivo e jogabilidade: localizar os navios adversários através de "tiros" dados verbalmente em uma matriz de linhas e colunas. Porém, a cada rodada, os alunos podem realizar uma "salva de tiros", que permite ao jogador efetuar mais de um tiro na mesma rodada. Esse ataque é concedido à equipe que for capaz de resolver um problema matemático, previamente, sorteado de uma lista. Os alunos envolveram-se no projeto e manifestaram, ao final, sua satisfação por terem momentos de aprendizado matemático que fogem à forma tradicional de ensino dessa ciência.
\end{abstract}

Palavras-chave: Jogos Matemáticos. Ludicidade. Ensino de Matemática.

\begin{abstract}
The work presents the report of the application of the game Naval Battle Mathematics as a playful element for the teaching of Mathematics. The activity was applied in a class of 7th grade of elementary school to teach the theme "equations of the 1st degree". The game follows the same logic as the traditional Naval Battle in terms of objective and gameplay: locating the opposing ships by verbally firing shots in an array of rows and columns. However, each round, students can perform a "round of fire", which allows the player to make more than one shot in the same round. This attack is awarded to the team that is capable of solving a mathematical problem previously drawn from a list. Students were involved in the project and expressed their satisfaction at the end of having moments of mathematical learning that are beyond the traditional way of teaching this science.
\end{abstract}

Keywords: Mathematical Games, Playfulness, Mathematics Teaching.

\footnotetext{
${ }^{1}$ Mestre em Matemática. professorandre@setelagoas.com.br

${ }^{2}$ Mestre em Matemática. walmisson.almeida@ifmg.edu.br

${ }^{3}$ Doutor em Educação Matemática. Professor no Instituto Federal de Minas Gerais e-mail: jose.fernandes@ifmg.edu.br
}

Tangram - Revista de Educação Matemática, Dourados - MS - v.2 n.4, pp. 106 - 117 (2019) 


\section{Batalha Naval Matemática: um relato da aplicação de jogos matemáticos no Ensino Fundamental}

\section{Introdução}

Nas perspectivas atuais relativas à Educação Matemática, discute-se a necessidade de uma postura cada vez mais dinâmica por parte dos docentes, a fim de trazer mais atratividade às aulas. Tal fato se justifica pela histórica dificuldade apresentada no âmbito do processo de ensino e aprendizagem da Matemática. A necessidade de se manter a motivação com relação aos estudos em Matemática faz com que o ambiente da sala de aula esteja em constante processo de reflexão (Guimarães, 2004). Sendo assim, de acordo com (Vockell, 2009), faz-se necessário que os docentes incluam elementos pedagógicos inovadores em suas práticas educativas que encorajem os alunos à aprendizagem. Nessa perspectiva, a aplicação de jogos matemáticos em sala de aula pode ser uma aliada para o desenvolvimento do protagonismo dos discentes (Grando, 2000).

Essa perspectiva de diversificação, ou seja, o uso de metodologias distintas no processo ensino e aprendizagem começou a ganhar força a partir da década de 90. Ela se faz presente desde os PCNs (Parâmetros Curriculares Nacionais) de 1998. Particularmente, o uso de jogos na Educação Matemática já era idealizado nesse documento:

É consensual a ideia de que não existe um caminho que possa ser identificado como único e melhor para o ensino de qualquer disciplina, em particular, da Matemática. No entanto, conhecer diversas possibilidades de trabalho em sala de aula é fundamental para que o professor construa sua prática. Dentre elas, destacam-se a História da Matemática, as tecnologias da comunicação e os jogos como recursos que podem fornecer os contextos dos problemas, como também os instrumentos para a construção das estratégias de resolução. (Brasil, 1998, p. 47)

No intuito de associar o ensino de Matemática ao uso de jogos lúdicos, este artigo apresenta o relato da aplicação de um jogo, adaptado do clássico "Batalha Naval", para uma turma de $7^{\circ}$ ano do Ensino Fundamental II de uma escola privada da cidade de Sete Lagoas, MG.

A atividade foi realizada levando em consideração as abordagens teóricas de Grando (2000). Segundo a citada autora, os jogos têm ocupado cada vez mais espaço como possível instrumento de ensino-aprendizagem de Matemática. Não na perspectiva de tornar o ambiente escolar mais palatável, mas também para atuar conjuntamente às aulas tradicionais na construção e fixação de modelos.

Tangram - Revista de Educação Matemática, Dourados - MS - v.2 n.4, pp. 106 - 117 (2019) 


\section{Batalha Naval Matemática: um relato da aplicação de jogos matemáticos no Ensino Fundamental}

Os jogos, as brincadeiras, enfim, as atividades lúdicas exercem um papel fundamental para o desenvolvimento cognitivo, afetivo, social e moral das crianças, representando um momento que necessita ser valorizado nas atividades infantis. O que se observa é que a criança, quando vai à escola, leva consigo um grande conhecimento sobre as brincadeiras e os jogos que está acostumada a praticar em sua casa, ou na rua, com seus colegas. É comum observarmos, no recreio, muitas destas brincadeiras se desenvolvendo. A questão que nos surge é: Por que, "no recreio", e não "na sala de aula"? Será que não poderíamos pensar em desenvolver um trabalho com esses jogos visando a construção de alguns conceitos e/ou habilidades matemáticas, tradicionalmente trabalhados pela escola? Será que estas crianças não ficariam muito mais interessadas a aprender se fosse através das próprias brincadeiras que elas estão acostumadas a fazer, ou de atividades semelhantes? Ou ainda, será que a sala de aula poderia ser um ambiente propício à reflexão e análise do jogo, a partir da intervenção pedagógica do professor responsável pelo grupo de alunos? (Grando, 2000, p.18)

Ainda de acordo com a autora, os jogos matemáticos trazem consigo uma possibilidade de melhoria das capacidades acadêmicas relacionadas a reconhecimento de padrões e raciocínio lógico-dedutivo:

O jogo de regras possibilita à criança a construção de relações quantitativas ou lógicas, que se caracterizam pela aprendizagem em raciocinar e demonstrar, questionar o como e o porquê dos erros e acertos. Neste sentido, o jogo de regras trabalha com a dedução, o que implica numa formulação lógica, baseada em um raciocínio hipotéticodedutivo, capaz de levar as crianças a formulações do tipo: teste de regularidades e variações, controle das condições favoráveis, observação das partidas e registro, análise dos riscos e possibilidades de cada jogada, pesquisar, problematizar sobre o jogo, produzindo conhecimento. (Grando, 2000, p. 31)

Borin (1996) corrobora com a linha do uso de jogos lúdicos na aprendizagem da

Matemática, pois, segundo a autora:

Outro motivo para a introdução de jogos nas aulas é a possibilidade de diminuir bloqueios apresentados por muitos de nossos alunos que temem a Matemática e sentem-se incapacitados para aprendê-la. Dentro da situação de jogo, na qual é impossível uma atitude passiva e a motivação é grande, notamos que, ao mesmo tempo em que estes alunos falam Matemática, apresentam também um melhor desempenho e atitudes mais positivas frente a seus processos de aprendizagem. (Borin, 1996, p. 9)

Mesmo com todos os benefícios que o uso de jogos pode trazer ao ensino de Matemática, sua prática ainda é pouco utilizada. E, quando se faz uso da citada metodologia, nem sempre ela é tratada com a devida seriedade. Segundo Ribeiro (2009, 


\section{Batalha Naval Matemática: um relato da aplicação de jogos matemáticos no Ensino Fundamental}

p.17), é importante que o docente desmistifique a ideia que "ao promover atividades com jogos, pode-se perder muito tempo ou ainda, não garantir a aprendizagem”.

Sendo assim, a estruturação de um plano de aula baseado no uso de jogos deve ser feita com muito critério para que, durante as atividades, não reste dúvidas ao discente que aquele é um momento de aprimoramento de habilidades matemáticas "[...] como observação, análise, levantamento de hipóteses, busca de suposições, reflexão, tomada de decisão, argumentação e organização, que estão estreitamente relacionados ao raciocínio lógico" (Smole, Diniz \& Cândido, 2007, p. 11). Ou seja, o aluno deve entender que aquele não é apenas um momento de descontração, mas sim de uma nova abordagem pedagógica para o ensino de Matemática.

Levando em consideração o exposto, realizou-se a experiência pedagógica visando subsidiar a aprendizagem e a consolidação de conceitos matemáticos relacionados ao tema "equações do $1^{\circ}$ grau". Ressalta-se que o estabelecimento de uma aula de Matemática mais dinâmica pode contribuir para uma boa relação que envolva a tríade Aluno $\leftrightarrow$ Professsor $\leftrightarrow$ Matemática, pois é fato que “[...] os fatores referentes à afetividade são decisivos no ensino e aprendizagem de matemática e que as relações estabelecidas entre os sujeitos e o saber matemático estão carregadas de afetividade, mesmo que isso seja pouco percebido pelos sujeitos envolvidos”(Otto, Dionízio, Brandt, 2019, p. 22).

O objetivo desse trabalho foi oferecer uma proposta auxiliar no ensino de Matemática para alunos do Ensino Fundamental II através do uso de jogos. Associados às diferentes metodologias de ensino, os jogos podem propiciar oportunidades de aprendizagem matemática mais agradável aos discentes e proporcionar um momento de interação e melhoria de relação entre alunos, professores e conteúdos da disciplina. Apesar da proposta apresentada nesse trabalho envolver somente o ensino de equações a alunos do Ensino Fundamental II, o jogo oferece liberdade para ser aplicado ao ensino de qualquer tema em qualquer nível escolar, inclusive em outras áreas do conhecimento.

\section{Apresentação do Jogo}

A base do projeto foi o jogo clássico "Batalha Naval" (Battleship, na primeira versão comercial, lançada nos EUA), disputado por dois jogadores. O jogo foi idealizado no período das Guerras Mundiais, na primeira metade do século XX. Cada jogador, na sua Tangram - Revista de Educação Matemática, Dourados - MS - v.2 n.4, pp. 106 - 117 (2019) 


\section{Batalha Naval Matemática: um relato da aplicação de jogos matemáticos no Ensino Fundamental}

vez, tem que adivinhar em quais quadradinhos estão as embarcações do oponente. O objetivo final do jogo consiste em derrubar todas as embarcações do adversário.

O jogo original é disputado em uma plataforma contendo duas malhas quadriculadas para cada jogador: na malha de defesa, o jogador representa a disposição das suas próprias embarcações; a outra malha, de ataque, representa a configuração do oponente. Nessa, o jogador vai armar suas estratégias e registrar os "tiros" realizados, marcando as partes das embarcações adversárias atingidas ou aqueles que atingiram a "água". As malhas quadriculadas são orientadas por números na horizontal e por letras na vertical.
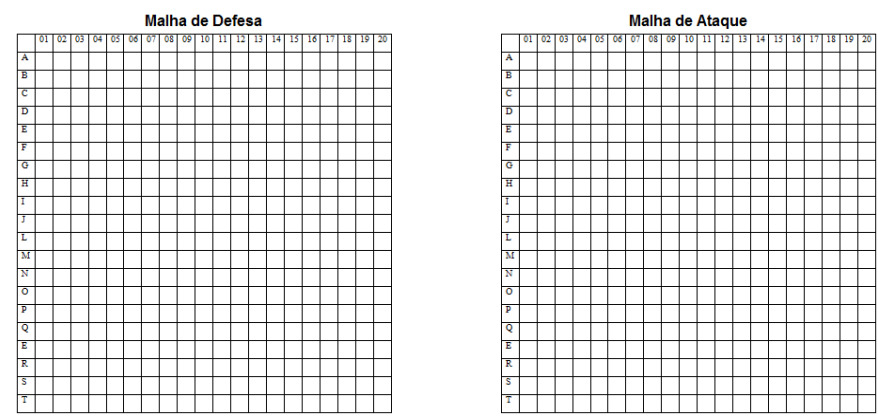

Figura 1 - Malha quadriculada de defesa e de ataque 20 x 20. Fonte: Elaborada pelos autores.

No jogo clássico, as embarcações são apresentadas por figuras quadriculadas. Como o jogo foi adaptado ao ensino de Matemática, optou-se por representar os seus elementos por figuras geométricas, como círculos, trapézios, triângulos, retângulos e suas combinações.
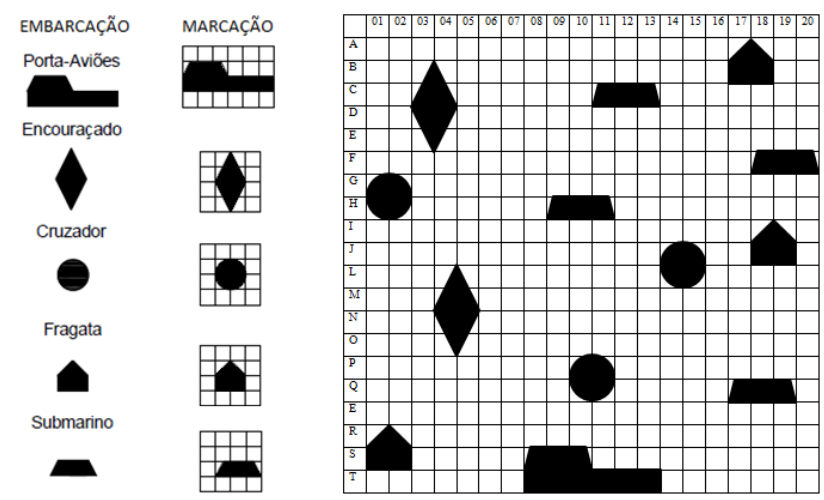

Figura 2 - Representação das embarcações e um exemplo de malha de defesa. Fonte: Elaborada pelos autores.

Nas figuras anteriores, ilustrou-se o caso do jogo em uma malha 20 x 20, com 13 embarcações. O tamanho da malha e a quantidade total de embarcações podem ser ajustados à proposta do docente e ao tempo disponível para sua aplicação.

Tangram - Revista de Educação Matemática, Dourados - MS - v.2 n.4, pp. 106 - 117 (2019) 


\section{Batalha Naval Matemática: um relato da aplicação de jogos matemáticos no Ensino Fundamental}

A partir do jogo clássico, surgiu a ideia de aprimorar o jogo "Batalha Naval" para deixá-lo mais dinâmico e divertido, com o uso de um elemento clássico de jogos eletrônicos de RTS (Real Time Strategy - Estratégia em Tempo Real) e RPG (RolePlaying Game - Jogo de Interpretação de Personagem): a utilização de cartas diversas que potencializam o poder de fogo dos jogadores. A seguir, as regras do jogo são descritas:

- O jogo Batalha Naval Matemática consiste em eliminar os navios da malha de defesa do adversário, assim como no jogo original. Porém, sugere-se o jogo em equipes (por exemplo, quatro ou seis jogadores), enquanto o Batalha Naval clássica envolve apenas dois jogadores;

- Para afundar os navios do oponente, o jogador deverá acertar tiros em diferentes lugares (quadradinhos) do navio adversário. A quantidade de tiros para afundar cada embarcação pode ser combinada previamente entre os jogadores. Cada tiro deve ser especificado por uma letra e um número, a fim de direcioná-lo à malha quadriculada do oponente;

- Cada participante, antes de realizar a jogada, irá retirar uma carta de um baralho que conterá perguntas e respostas de conteúdos de Matemática;

- Cada carta, ao ser retirada pelo jogador, será entregue à equipe adversária, que fará a pergunta. Caso a equipe acerte o resultado, poderá efetuar uma "salva de tiros". Essa salva consiste na realização de 3 tiros simultâneos, em diferentes locais da malha adversária;

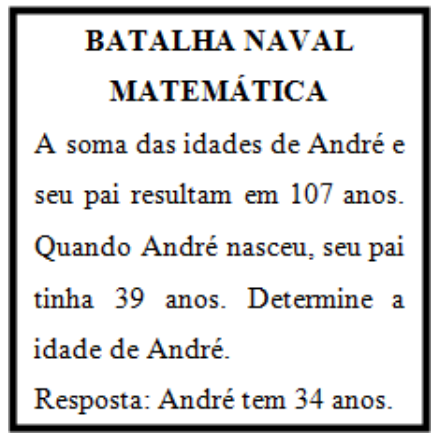

Figura 3 - Modelo de carta para potencializar o ataque.

Fonte: Elaborada pelos autores.

- Pode-se definir, antes de iniciada a partida, se as perguntas serão respondidas individualmente (apenas o jogador da vez) ou por toda a equipe. Pode-se definir

Tangram - Revista de Educação Matemática, Dourados - MS - v.2 n.4, pp. 106 - 117 (2019) 


\section{Batalha Naval Matemática: um relato da aplicação de jogos matemáticos no Ensino Fundamental}

também um tempo para a emissão da resposta (tempo esse bem dimensionado para que o jogo não se torne demasiadamente longo);

- O conteúdo dessas cartas deve variar em níveis fácil, médio e difícil, para promover certa aleatoriedade no sorteio, de modo a propiciar surpresa a cada rodada.

As malhas para a realização do jogo podem ser impressas em papel comum. Desse modo, o jogo envolve o uso apenas de papel e caneta, sendo de baixíssimo custo para sua realização.

\section{Desenvolvimento da Atividade}

O jogo foi aplicado para os alunos do $7^{\circ}$ ano do Ensino Fundamental II de uma escola privada da cidade de Sete Lagoas. Os discentes haviam finalizado os estudos sobre teoria e resolução de equações do $1^{\circ}$ grau, inclusive executando problemas que envolviam modelagem matemática. Dessa forma, as cartas versavam sobre situações-problema relativas ao tema.

Em um primeiro momento, realizou-se uma breve introdução da proposta e seus objetivos. Não houve nenhuma surpresa por parte dos discentes, visto que o uso de formas lúdicas de ensino é habitual nas aulas de Matemática da turma. Sendo assim, agendou-se a data de aplicação da atividade, os alunos foram orientados sobre o jogo e suas regras, formaram as suas duplas e assim iniciaram as partidas.

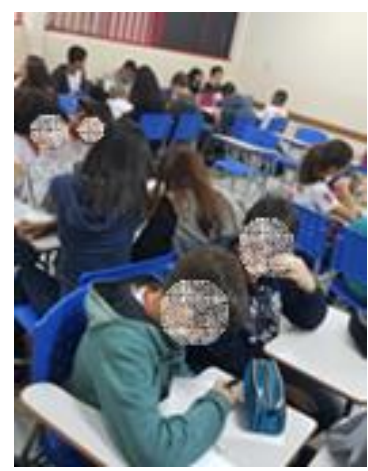

Figura 4 - Sala de aula preparada para a aplicação do jogo.

Fonte: Arquivo dos autores.

Antes da rodada inicial, cada dupla incumbiu-se de elaborar estrategicamente a sua malha de defesa. Foi orientado pelo docente que cada equipe distribuiria duas embarcações Tangram - Revista de Educação Matemática, Dourados - MS - v.2 n.4, pp. 106 - 117 (2019) 


\section{Batalha Naval Matemática: um relato da aplicação de jogos matemáticos no Ensino Fundamental}

de cada tipo pré-estabelecido, segundo o modelo impresso em folha A4, entregue aos alunos.

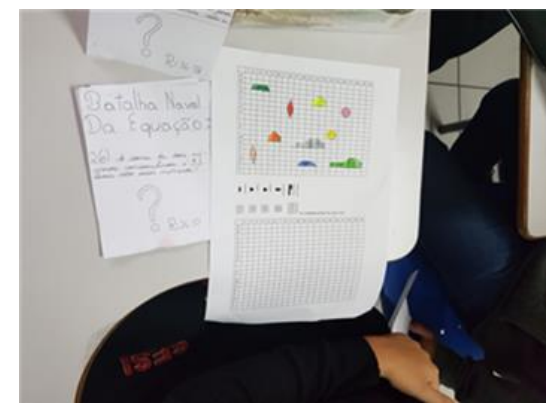

Figura 5 - Montagem de uma malha de defesa e uma carta do jogo.

Fonte: Arquivo dos autores.

Iniciadas as partidas, após a retirada de cada carta, os oponentes liam o problema, enquanto os jogadores organizavam os dados e tentavam montar e resolver a equação. Ao final do tempo delimitado para a resolução (ou logo que chegavam ao resultado), respondiam e, caso acertassem, poderiam fazer a jogada com a "salva de tiros". Caso errassem, tinham direito a um tiro, apenas. O tempo de espera para resolução foi combinado entre cada equipe.

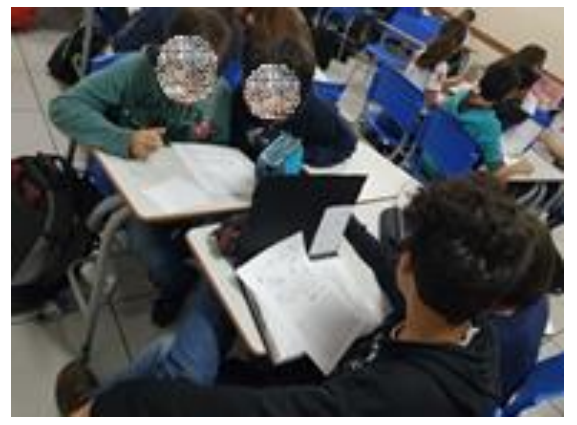

Figura 6 - Resolução dos problemas em equipe, após leitura da carta.

Fonte: Arquivo dos autores.

Os alunos se mantiveram envolvidos na dinâmica e ficou evidente, durante a execução da proposta, a competitividade saudável entre as equipes. Houve esforço de todos na resolução dos problemas, indo de encontro à perspectiva de desistência comumente observada em aulas de Matemática, muito provavelmente por se tratar de um jogo. A seguir, apresenta-se o conteúdo de algumas das cartas, os quais foram considerados representativos no contexto da atividade:

Tangram - Revista de Educação Matemática, Dourados - MS - v.2 n.4, pp. 106 - 117 (2019) 


\section{Batalha Naval Matemática: um relato da aplicação de jogos matemáticos no Ensino Fundamental}

- Pensei em um número que multiplicado por 8 e subtraído 16 dá 64. Qual é esse número?

- Júnior e Luís jogam na mesma equipe de basquete. No último jogo dessa equipe, os dois juntos marcaram 52 pontos. Júnior marcou 10 pontos a mais que Luís. Quantos pontos Júnior marcou nessa partida?

- Uma fita de 247 metros vai ser dividida em duas partes, de modo que uma tenha 37 metros a mais que a outra. Quanto mede a parte maior?

- A soma da minha idade com a idade de meu irmão, que é 7 anos mais velho que eu, dá 37 anos. Quantos anos eu tenho de idade?

- O triplo de um número menos 10 é igual ao dobro desse mesmo número menos 78. Qual é esse número?

- Cada aluno da $7^{a}$ série ofereceu à Associação de Pais e Mestres 6 canetas esferográficas para distribuir entre os alunos carentes. Foram arrecadadas 252 canetas. Quantos alunos tem a essa turma?

- Mariângela possui $R \$ 49,00$. Com essa quantia, ela pode ir três vezes ao cinema e ainda lhe restarão $R \$ 16,00$. Qual o valor do ingresso do cinema?

- Um prêmio de $R \$ 500,00$ foi repartido entre Sibele e Fernanda, de modo que Sibele recebeu $R \$$ 80,00 mais que Fernanda. Qual o prêmio recebido por Fernanda?

- Quando Eduardo nasceu, seu pai tinha 35 anos. A soma de suas idades atuais é 65 anos. Qual a idade de Eduardo?

- A soma de dois números ímpares consecutivos é 88. Quais são esses números?

\section{Resultados e Discussões}

$\mathrm{Na}$ aula posterior à dinâmica, o professor realizou um debate com a turma para avaliação qualitativa da proposta. Analisando-se o padrão das duplas que tiveram maior êxito, foi possível perceber que essas foram as que mais conseguiram resolver corretamente os problemas apresentados nas cartas. Isso não pode ser visto com surpresa já que, ao disparar a salva de tiros, triplica-se a chance de sucesso na jogada. Porém, ciente da potencialidade do jogo, o professor encarregou-se de mobilizar todas as equipes, indiferente dos resultados obtidos, o que gerou uma unanimidade de relatos sobre o aspecto positivo da participação na tarefa.

A seguir, são apresentados dois relatos de alunos sobre as suas impressões com relação à atividade realizada. Os perfis destes alunos são de destaque estudantil, tanto na participação quanto no rendimento escolar. As opiniões foram transcritas na íntegra:

A Batalha Naval Matemática foi um jogo proposto pelo professor para auxiliar e reforçar o aprendizado sobre equações, pois alguns alunos estavam com dificuldade de aprender da forma trivial. O jogo era em grupo com 4 pessoas, onde nós mesmos montamos as tabelas e as cartas. Das 4 pessoas, duas faziam uma dupla e as outras duas Tangram - Revista de Educação Matemática, Dourados - MS - v.2 n.4, pp. 106 - 117 (2019) 


\section{Batalha Naval Matemática: um relato da aplicação de jogos matemáticos no Ensino Fundamental}

faziam outra dupla. Cada dupla dizia um problema envolvendo uma equação, e os rivais deveriam resolver esse problema. Quem acertasse o problema, tinha vantagem de atirar. Esse jogo é uma forma mais divertida e dinâmica de aprendizagem, onde nós conseguimos aprender sem que a aula fique apenas com muitas falas do professor. O jogo foi proposto após o professor já ter explicado a matéria e corrigido exercícios, ou seja, os alunos já sabiam como resolver uma equação. Foi uma forma excelente de fixar a matéria e tirar o resto das dúvidas que os alunos tinham. Esperamos ter mais oportunidades de fixação de matérias como foi esta. (ALUNA 1).

O exposto pela Aluna 1 faz-nos refletir sobre a prática pedagógica em Matemática que, segundo Grando (2000) deve-se encarregar de melhorar o ensino desta ciência, aproximando o aluno da construção do objeto de conhecimento. Complementando o relato da Aluna 1, o Aluno 2 pondera que:

A atividade realizada em sala de aula se baseou em um jogo de Batalha Naval, como incorporação de equações. Como ampliação na Matemática, podemos citar o estudo de coordenadas, probabilidade, estratégia, raciocínio lógico e áreas. Com a introdução das cartas de poder, a pessoa poderia resolver a mesma e quando dava o resultado correto, falava um comando. Caso houvesse uma embarcação naquele local, poderia dar mais tiros de uma vez. Através dessa experiência, podemos perceber a participação da matemática não só em jogos, mas em tudo que fazemos. Foi uma forma divertida e diferente de aprender. Toda a turma gostou e ficou querendo mais aulas deste tipo. (ALUNO 2).

Observa-se no relato desse aluno a importância do uso de jogos como recurso para abordar diferentes temáticas de uma mesma área ou, até mesmo, relacionar a Matemática com o cotidiano. Esse pode ser um dos motivos para usar o jogo além do caráter motivacional, entendendo-o como uma ação que deve ser planejada, executada, registrada, avaliada e compartilhada pelos alunos e professores, conforme afirma Grando (2007).

Ao fim da aula, o professor promoveu uma reflexão sobre a importância da Matemática no âmbito das sociedades. Inclusive, discutiu-se a importância dessa área do conhecimento para o desenvolvimento de tecnologias que promovem a qualidade de vida do ser humano bem como o seu uso para fins que fogem aos padrões éticos da ciência, como as guerras.

Tangram - Revista de Educação Matemática, Dourados - MS - v.2 n.4, pp. 106 - 117 (2019) 


\section{Batalha Naval Matemática: um relato da aplicação de jogos matemáticos no Ensino Fundamental}

\section{Considerações Finais}

Para tecer essas considerações, é importante retomar ao objetivo da aula que foi o uso do jogo Batalha Naval Matemática numa turma do $7^{\circ}$ ano do Ensino Fundamental II para revisar e/ou ressignificar conceitos de equações do $1^{\circ}$ grau. Inicialmente, ocorreu uma reflexão sobre qual jogo utilizar e qual seria sua contribuição. Tal reflexão foi importante, pois a escolha de um jogo exige cuidado e planejamento; ao contrário, perde-se a possibilidade da contribuição deste recurso na construção ou na ressignificação de conhecimentos matemáticos. Pelos relatos dos estudantes e pelas observações realizadas, foi possível perceber que o jogo utilizado promoveu descontração, interação e contribuições para o processo de ensino aprendizagem.

A opção pelo uso do jogo deve ser apoiada pelo planejamento responsável e por reflexões sobre sua contribuição à construção do conhecimento matemático. Neste aspecto, vale ressaltar que, ao longo da aula na qual foi utilizado o jogo proposto, os alunos se envolveram, cooperativamente, resolvendo os problemas valendo de conjecturas, cálculo mental e resoluções escritas (numéricas e pictóricas).

Outro aspecto importante é o papel do professor que passou ser de orientador e mobilizador do processo, culminando no estabelecimento de interações importantes e necessárias à aula de Matemática. Historicamente, a sala de aula de Matemática tem sido caracterizada como sendo um ambiente onde os professores explicam os conteúdos, os alunos resolvem as atividades propostas e, realiza-se a correção. Essa dinâmica, embora legítima, não favorece a inclusão dos alunos que apresentam dificuldades e/ou desinteresse pela Matemática.

Entende-se que a experiência com o Jogo Batalha Naval Matemática aproxima das reflexões de Grando quando defende que o uso do jogo deve favorecer aos alunos “[...] estabelecer relações, antecipar jogadas, elaborar estratégias, tematizar/fundamentar e encontrar razões para as jogadas, aproveitando as jogadas do adversário, interpretando-as e observando regularidades". (Grando, 2000, p. 57)

Um aspecto importante do jogo utilizado é a possibilidade de poder ampliá-lo, incluir e/ou alterar suas regras, inclusive com a participação dos alunos. Outro ponto a considerar é a possibilidade de trabalhar com outros conteúdos, tanto na fase inicial da abordagem dos mesmos, quanto para revisar e/ou fixar conceitos.

Para finalizar essas reflexões, vale recorrer aos dizeres de Grando (2000):

Tangram - Revista de Educação Matemática, Dourados - MS - v.2 n.4, pp. 106 - 117 (2019) 


\section{Batalha Naval Matemática: um relato da aplicação de jogos matemáticos no Ensino Fundamental}

É muito importante propiciar, em situações escolares, momentos de atividades de trabalho em grupo, para que os sujeitos sejam capazes de compreender e respeitar as formas de participação dos colegas de trabalho. Além do que, tratase de um exercício para o próprio autoconhecimento. Em atividades grupais, os sujeitos são capazes de se conhecer, conhecer mais seus próprios limites, atitudes, valores e capacidades, a fim de contribuir para que o trabalho se desenvolva da melhor forma. (Grando, 2000, p. 91)

Tal perspectiva pode contribuir para um processo de socialização e humanização das relações, uma vez que a sociedade contemporânea vive processos de isolamento social, individualismo, competições desenfreadas e ausência de cooperativismo. A sala de aula, como um extrato dessa sociedade atual, apresenta muito fortemente tais características. É dever dos educadores buscar estratégias e recursos que possam contribuir positivamente na formação das crianças, jovens e adolescentes.

\section{Referências}

Borin, J. (1996). Jogos e resolução de problemas: uma estratégia para as aulas de matemática. São Paulo: IME/USP.

Grando, R. C. (2000). O conhecimento matemático e o uso de jogos na sala de aula. Dissertação (Tese de Doutorado) - Faculdade de Educação, UNICAMP, Campinas.

Grando, R. C. (2007). Concepções quanto ao uso de jogos no ensino da Matemática. Revista de Educação Matemática, v. 10, (p. 45-52).

Guimarães, S. E. R.; Boruchovitch, E. (2004). O estilo motivacional do professor e a motivação intrínseca dos estudantes: uma perspectiva da Teoria da Autodeterminação. Psicologia: Reflexão e Crítica, v.17, n. 2, Porto Alegre - RS. (p.143-150).

Brasil - Ministério da Educação - Secretaria de Educação Fundamental. (1998). PCNs Parâmetros Curriculares Nacionais. Brasília: MEC/SEF.

Otto, M. C; Dionizio, F. A. Q.; Brand, C. F. (2019). O papel das crenças e emoções no desenvolvimento da afetividade em relação à matemática nos anos iniciais do ensino fundamental. Tangram - Revista de Educação Matemática. v.2, n.2, Dourados - MS. (p. 03-24).

Ribeiro, F. D. (2009). Jogos e modelagem na educação matemática. São Paulo: Saraiva.

Smole, K. S; Diniz, M. I. \& Cândido, P. (2007). Jogos de matemática de $1^{\circ}$ a $5^{\circ}$ ano. Cadernos do Mathema - Ensino Fundamental. Porto Alegre: Artmed.

Vockell, E. L. (2009). Educational Psychology: A Practical Approach. Calumet. Purdue University - Calumet.

Enviado: 05/09/2019

Aceito:14/10/2019

Tangram - Revista de Educação Matemática, Dourados - MS - v.2 n.4, pp. 106 - 117 (2019) 